\title{
Does a Positive HLA-B27 Test Increase Your Risk of Mortality?
}

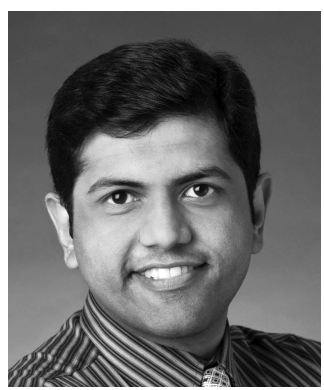

HLA-B27 is a major histocompatibility class I (MHC-I) molecule that plays a role in antigen presentation. It is well known for its strong association with ankylosing spondylitis (AS), a link discovered more than 40 years ago. HLA-B27 positivity in the white population carries a 20 -fold increased risk of developing spondyloarthritis $(\mathrm{SpA})^{1}$. Prevalence of AS mirrors the HLA-B27 prevalence across the world, with the highest prevalence of HLA-B27 reported in Haida Indians at $50 \%$ to Japan at $0.1 \%$. At the time of this publication at least 132 subtypes of HLA-B27 have been identified according to the Immuno Polymorphism Database $^{2}$. The prevalence of HLA-B27 in the white population is around $6 \%$ to $8 \%$, with HLA-B*2705 being the predominant subtype.

HLA-B27 is present in $85 \%$ of white patients with AS. However, less than 5\% of HLA-B27-positive people ever develop AS. Apart from AS, other diseases associated with HLA-B27 are uveitis, psoriatic arthritis, and lone aortic regurgitation. Patients with HLA-B27 have a survival advantage with human immunodeficiency virus (HIV) and hepatitis $\mathrm{C}$ virus infection. It is thought to be due to the presence of virus-specific peptides on HLA-B27 that are recognized by protective $\mathrm{CD} 8+\mathrm{T}$ cells ${ }^{3}$. There is a latitude-dependent difference in the distribution of HLA-B27, with higher latitudes including the high Arctic and sub-Arctic areas having much higher prevalence compared to the equatorial regions. Malaria is endemic in areas of Africa with lower prevalence of HLA-B274. Could this be caused by increased malaria-related mortality in HLA-B27+ individuals? Over a period of years, selection pressures could have led to the HLA-B27 distribution differences evident now. A study from Mumbai suggested that patients with malaria were more likely to be HLA-B27positive compared to controls, but there was no comparison of mortality figures ${ }^{5}$. Similarly to reports of HLA-B27 subtype association with AS, recent studies suggest that protection in HIV may be HLA-B27 subtype-specific ${ }^{6}$. A similar subtype-dependent difference in infections endemic to different parts of the world could have led to selection pressures and hence the differences in HLA-B27 subtype distribution across the world.

Survival benefits or susceptibility to deaths in HLA-B27, as outlined above, have been discussed predominantly in the context of infections. In this issue of The Journal, Walsh and colleagues, using a historical cohort of US veterans enrolled in the Veterans Health Administration (VHA), report an increase in mortality risk of HLA-B27-positive versus HLA-B27-negative veterans ${ }^{7}$. More than 32,000 veterans who were tested for HLA-B27 were part of this study, and around 5000 had the B27 gene. Patients who were diagnosed to have SpA were identified by ICD 9 codes used by a rheumatologist. The cohort was followed for a mean period of 4.6 to 4.8 years, and mortality rates were compared between the HLA-B27-positive and HLA-B27-negative groups. After controlling for several baseline variables including age, sex, comorbidities, and SpA, there was a marginal $15 \%$ increase in risk of mortality in HLA-B27-positive veterans. Around $35 \%$ of the HLA-B27-positive group had SpA and 2.4\% had some other form of inflammatory arthritis. Around 22\% of patients in the HLA-B27-positive group were receiving biologic disease-modifying antirheumatic drugs and likely, the patients with SpA had severe disease. There was no information on nonsteroidal antiinflammatory drug (NSAID) use and cause of death. When patients with and without SpA were assessed separately, the difference in mortality rate remained significant only in the subgroup with SpA. The time from HLA-B27 testing to mortality or end of study was selected as the timescale rather than age at outcome. Because HLA-B27 is present from birth, age at outcome would seem to be the logical time scale, but the age at HLA-B27 testing was included as a covariate in the Cox proportional hazards model, which is acceptable and should adjust the results for varying age of testing.

This is an interesting report that looks at a hard and important outcome in patients who are positive for a commonly done test. HLA-B27 testing is recommended in the appropriate clinical setting ${ }^{8}$. Reveille and colleagues

\section{See Mortality in American veterans with HLA-B27, page 638, and Choosing wisely, page 682}

Personal non-commercial use only. The Journal of Rheumatology Copyright @e 2015. All rights reserved. 
reported the US age-adjusted prevalence of HLA-B27 at $6.1 \%$, but found the prevalence to be decreased to $3.6 \%$ in the age group 50-69 years ${ }^{9}$. Although a possibility of increased mortality of HLA-B27-positive individuals was considered, additional analysis with patients categorized by the decade failed to show a linear decreasing trend ${ }^{9}$. The Reveille, et al study has the merit of including a nationally representative sample of the population, and HLA-B27 was not tested on clinical indications. Increased mortality in patients with AS has been reported in the past, with infections and cardiovascular causes predominating $10,11,12,13,14$. Chronic inflammation, valvular heart disease, arrhythmias, impaired mobility, and restricted chest and lung expansion could be direct AS-related causes of mortality ${ }^{15,16}$

Several points should be kept in mind while interpreting this article. HLA-B27 positivity in patients without a diagnosis of SpA did not significantly affect mortality. Less than 5\% of those who test positive for the HLA-B27 test will have SpA, and the results of this study may not be generalizable to the vast majority of HLA-B27-positive individuals without SpA. Possibly the increased mortality in SpA drove the mortality rates in HLA-B27-positive veterans. Interestingly, adjustment for biologics did not affect the results. NSAID are an important part of the equation when considering mortality but they are very difficult to control for, especially in retrospective studies. The mean age of 52 years at testing is higher than the typical age of presentation of patients with inflammatory spinal arthritis. The HLA-B27 test was done for clinical indications in patients who were likely less healthy than the general population and with higher baseline morbidity and mortality risk. An important missing part of the story is the cause of death, without which it is difficult to draw any firm conclusions.

The Choosing Wisely initiative by the Canadian Rheumatology Association, also reported in this issue, clearly states that HLA-B27 testing is not a useful diagnostic test in a patient with isolated low back pain and no other SpA signs or symptoms ${ }^{17}$. HLA-B27 testing should still be reserved for the appropriate scenario to complement a clinical diagnosis of SpA. Increasing evidence for higher rates of vascular mortality in AS patients should prompt development of an adequate protocol for comorbidity screening and management.

\footnotetext{
NIGIL HAROON, MD, PhD, DM,

Assistant Professor,

Division of Rheumatology, Department of Medicine,

University of Toronto;

Clinician Scientist and Attending Physician,

University Health Network,

Affiliate Scientist, Toronto Western Research Institute

Toronto, Ontario, Canada.
}

Address correspondence to Dr. N. Haroon, 1E-425, 399 Bathurst St.,

Toronto Western Hospital, Toronto M5T 2S8, Ontario, Canada.

E-mail: nigil.haroon@uhn.ca

\section{REFERENCES}

1. Braun J, Bollow M, Remlinger G, Eggens U, Rudwaleit M, Distler A, et al. Prevalence of spondylarthropathies in HLA-B27 positive and negative blood donors. Arthritis Rheum 1998;41:58-67.

2. EMBL-European Bioinformatics Institute. Immuno Polymorphism Database. [Internet. Accessed January 27, 2015.] Available from: www.ebi.ac.uk/ipd/

3. Schmidt J, Iversen AK, Tenzer S, Gostick E, Price DA, Lohmann V, et al. Rapid antigen processing and presentation of a protective and immunodominant HLA-B*27-restricted hepatitis C virus-specific CD8+ T-cell epitope. PLoS Pathog 2012;8:e1003042.

4. Mathieu A, Cauli A, Fiorillo MT, Sorrentino R. HLA-B27 and ankylosing spondylitis geographic distribution as the result of a genetic selection induced by malaria endemic? A review supporting the hypothesis. Autoimmun Rev 2008;7:398-403.

5. Shankarkumar U, Devaraj JP, Ghosh K, Karnad D, Anand K, Mohanty D. HLA associations in P. falciparum malaria patients from Mumbai, western India. Indian J Malariol 2002;39:76-82.

6. Nitschke K, Barriga A, Schmidt J, Timm J, Viazov S, Kuntzen T, et al. HLA-B*27 subtype specificity determines targeting and viral evolution of a hepatitis $\mathrm{C}$ virus-specific CD8+ T cell epitope. J Hepatol 2014;60:22-9.

7. Walsh JA, Zhou X, Clegg DO, Teng C, Cannon GW, Sauer B Mortality in American veterans with HLA-B27. J Rheumatol 2015;42:638-44.

8. Chow S, Haroon N. A 24-year-old man with suspected sacroiliitis. CMAJ 2014 Dec 22 (E-pub ahead of print).

9. Reveille JD, Hirsch R, Dillon CF, Carroll MD, Weisman MH. The prevalence of HLA-B27 in the US: data from the US National Health and Nutrition Examination Survey, 2009. Arthritis Rheum 2012;64:1407-11.

10. Lehtinen K. Mortality and causes of death in 398 patients admitted to hospital with ankylosing spondylitis. Ann Rheum Dis 1993;52:174-6.

11. Khan MA, Khan MK, Kushner I. Survival among patients with ankylosing spondylitis: a life-table analysis. J Rheumatol 1981;8:86-90

12. Zochling J, Braun J. Mortality in ankylosing spondylitis. Clin Exp Rheumatol 2008;26 Suppl 51:S80-4.

13. Zochling J, Braun J. Mortality in rheumatoid arthritis and ankylosing spondylitis. Clin Exp Rheumatol 2009;27 Suppl 55:S127-30.

14. Mok CC, Kwok CL, Ho LY, Chan PT, Yip SF. Life expectancy, standardized mortality ratios, and causes of death in six rheumatic diseases in Hong Kong, China. Arthritis Rheum 2011;63:1182-9.

15. Hamdi W, Chelli Bouaziz M, Zouch I, Ghannouchi MM, Haouel M, Ladeb MF, et al. Assessment of preclinical atherosclerosis in patients with ankylosing spondylitis. J Rheumatol 2012;39:322-6.

16. Kanathur N, Lee-Chiong T. Pulmonary manifestations of ankylosing spondylitis. Clin Chest Med 2010;31:547-54.

17. Chow SL, Thorne JC, Bell MJ, Ferrari R, Bagheri Z, Boyd T, et al. Choosing Wisely: The Canadian Rheumatology Association's list of 5 items physicians and patients should question. J Rheumatol 2015;42:682-9.

J Rheumatol 2015;42:559-60; doi:10.3899/jrheum.150017

Personal non-commercial use only. The Journal of Rheumatology Copyright (c) 2015. All rights reserved. 